\title{
Variants of Folate Metabolism Genes and Risk of Left-Sided Cardiac Defects
}

\author{
Laura E. Mitchell ${ }^{1}$, Jin Long ${ }^{1}$, Jennifer Garbarini, Prasuna Paluru, and Elizabeth \\ Goldmuntz ${ }^{1}$ \\ ${ }^{1}$ Institute of Biosciences and Technology, Texas A\&M University System Health Science Center, \\ Houston TX 77030, USA \\ ${ }^{2}$ Children's Hospital of Philadelphia, PA, USA
}

\section{Abstract}

Background-Congenital heart defects (CHD) are the most common, serious group of birth defects. Although relatively little is known about the causes of these conditions and there are no established prevention strategies, evidence suggests that the risk of CHD may be related to maternal folate status as well as genetic variants in folate-related genes. Efforts to establish the relationships between these factors and CHD risk have, however, been hampered by a number of factors, including small study sample sizes and phenotypic heterogeneity.

Methods-The present study examined the relationship between nine genetic variants in eight folate-related genes and a relatively homogeneous group of left-sided cardiac defects in a cohort of 386 case-parent triads. Log-linear analyses were used to assess both maternal and inherited genetic effects.

Results-Analyses of the study data provided marginal evidence that the maternal MTR A2756G (unadjusted $\mathrm{p}=0.01$ ) and the inherited $B H M T$ G742A genotypes (unadjusted $\mathrm{p}=0.06$ ) influence the risk of this subset of CHD. However, neither association achieved significance when the falsediscovery rate was controlled at 0.05 .

Conclusions-These results, which are based on the largest study sample and most comprehensive assessment of the relationship between left-sided cardiac defects and folate-related genes reported to date, provide little evidence that this subset of CHD is folate-related. However, even larger studies and more comprehensive evaluations of the folate pathway genes are required to fully explore the relationship between folate and left-sided cardiac defects.

\section{Keywords}

birth defect; folate; folic acid; gene; heart

\section{Introduction}

Congenital heart defects (CHD) are the most common, serious birth defects of genetic or partially genetic origin (Christianson and others, 2006). Despite medical and surgical improvements, CHD continue to be associated with significant lifelong morbidity and early mortality (Boneva and others, 2001). In addition, relatively little is known about the causes

\footnotetext{
Address for Correspondence: Elizabeth Goldmuntz, MD, Division of Cardiology, The Children's Hospital of Philadelphia, Abramson Research Center 702A, 3615 Civic Center Boulevard, Philadelphia, PA 19104-4318, 215-590-5820 (t), 215-590-5454 (f), goldmuntz@email.chop.edu.

Presented at The American Society of Human Genetics $56^{\text {th }}$ Annual Meeting, October $9-13^{\text {th }}, 2006$, New Orleans, LA.
} 
of these conditions, and there are no established strategies for reducing their public health impact (Jenkins and others, 2007).

As a group, CHD include a range of malformations that are anatomically, epidemiologically, developmentally and clinically heterogeneous. Nonetheless, there is evidence that subgroups of CHD share common risk factors and are, therefore, more similar to each other than to other forms of CHD (Botto and others, 2007). One such subgroup includes malformations of the left sided structures of the heart, or left-sided lesions (LSL). Component members of this subgroup of CHD (i.e. LSL) include hypoplastic left heart syndrome (HLHS), coarctation of the aorta (COA) and aortic valve stenosis (AS). Family studies, which demonstrate that the affected relatives of individuals with LSLs are more likely to have a LSL than other type of CHD, indicate that the various LSL share common genetic underpinnings (Botto and others, 2007; Corone and others, 1983; Cripe and others, 2004; Ferencz and others, 1989; Fraser and Hunter, 1975; Hinton and others, 2007; Lewin and others, 2004; McBride and others, 2005).

The established causes of CHD are individually quite rare and for most affected individuals a specific causative agent or gene cannot be identified (Jenkins and others, 2007; Pierpont and others, 2007). However, there is evidence that, similar to neural tube defects, the risk of CHD, including LSL, may be influenced by maternal folate status [reviewed in (Botto and others, 2000; 2003; Jenkins and others, 2007)] as well as variation within genes that are involved in folate-transport and metabolism (Botto and others, 2000; Goldmuntz and others, 2008; Hobbs and others, 2006; Pei and others, 2006; Shaw and others, 2005; Shaw and others, 2003; van Beynum and others, 2007; Verkleij-Hagoort and others, 2008). However, associations with maternal folate status and folate-related genes have not been established for CHD in general, or for specific subsets of CHD (Pierpont and others, 2007). Hence, the present study was undertaken to assess the associations between a relatively homogeneous subset of CHD (i.e. LSL) and variants within folate-metabolism genes that have previously been identified as potential risk factors for CHD and other common birth defects.

\section{Methods}

\section{Study Subjects}

The present study is based on data from 368 case-parent triads, recruited between 1997 and 2007 from the Cardiac Center at The Children's Hospital of Philadelphia and in accordance with a protocol approved by the Institutional Review Board for the Protection of Human Subjects. Study subjects included those with the left-sided cardiac lesions: hypoplastic left heart syndrome (HLHS), coarctation of the aorta with or without a bicuspid aortic valve (CA), aortic valve stenosis (AS), isolated mitral valve anomalies, and a small number with other left sided defects. Patients with so-called "HLHS variants" such as malaligned atrioventricular canal defects or double outlet right ventricle with mitral valve atresia were excluded.

Males and females, and individuals of any racial/ethnic group were eligible to participate in the study. Blood samples were collected from study subjects, prior to a blood transfusion, at the time of surgical or medical intervention, and blood, buccal or saliva samples were collected from each available parent. Cases with a recognized genetic syndrome or chromosome anomaly, including those with Turner syndrome, were excluded from the current analyses. Medical records including, when necessary, original imaging studies, were reviewed to confirm the cardiac diagnosis and identify additional medical issues. 


\section{Genotyping Methods}

Case and parental DNA was extracted from whole blood, buccal swabs or lymphoblastoid cell lines using standard methods (Puregene DNA isolation kit by Gentra System Inc., Minneapolis MN). Duplicate samples were included both within and across plates such that $5 \%$ of the samples were genotyped three times. The study cohort was genotyped for nine single nucleotide polymorphisms (SNPs) from eight genes: MTHFR C677T and A1298C, MTR A2756G, MTRR A66G, NOS3 G894T, BHMT G742A, SHMT C1420T, TCN2 C777G and $M C P 1$ (-A2518G). The genes selected for analysis are involved in folate-homocysteine metabolism. Specific variants were selected for genotyping based on previous studies demonstrating an association between the variant and risk of CHD or another structural birth defect and/or evidence that the variant influences protein function.

SNP genotyping was conducted in the High-Throughput Genotyping Core Laboratory at the Molecular Diagnosis and Genotyping Facility at the University of Pennsylvania, using the ABI 7900 HT Sequence Detection System (Applied Biosystems, Inc., Foster City, CA). Taqman 5' nuclease polymerase chain reaction (PCR) primers and probes for the variant of interest were ordered (Assays-on-Demand) or custom designed (Assay-By-Design) by Applied Biosystems (Foster City, CA) or Epoch Biosciences (Nanogen and currently Sigma Aldrich; St. Louis, MO). To validate each assay, the primer and probe sets were tested on a panel of DNA samples composed of CEPH family members (Family 1331, XC01331) obtained from Coriell Human Variation Collection (Coriell Institute, Camden, NJ). PCR amplifications were subsequently performed in a 384-well plate format with appropriate controls and processed according to the manufacturer's instructions (Applied Biosystems, Inc., Foster City, CA). Allelic discrimination results were graphed on a scatter plot and data transferred electronically for analysis.

\section{Statistical Methods}

The characteristics of the case individuals and their parents were summarized using counts and proportions. In addition, for each analyzed variant, the proportion of samples for which a genotype could not be assigned, the proportion of samples that yielded discrepant results on repeated genotypes, and the proportion of triads that had genotype combinations that were incompatible with Mendelian inheritance were determined. For each sample, the number of genotyping failures (i.e. genotypes that could not be assigned or were discrepant across repeated genotypes) was determined. These analyses were performed using SAS version 9.1 (SAS Institute, Inc, Cary, NC).

Log-linear analyses were used to assess the association between LSL and both the inherited (i.e. case) and maternal genotypes for each variant (Weinberg and others, 1998). For simplicity, the most common genotype for each variant was designated as the referent category. The risk of LSL in cases and the risk of having a child with a LSL in mothers of cases with the heterozygous or rare homozygous genotypes, relative to cases and mothers with the common homozygous genotype were estimated along with associated $95 \%$ confidence intervals. The significance of the inherited and maternal genetic effects was determined using the likelihood ratio test to compare the log-linear model that included terms for both the inherited and maternal genotypes, with reduced models that included terms for only the inherited or only the maternal genotype. In general, an unrestricted model, which allowed the relative risks associated with the heterozygous and rare homozygous genotypes to vary independently, was fitted to the data. However, when the number of cases or mothers with the rare homozygous genotype was small $(\mathrm{N} \leq 10)$, a dominant model of inheritance was fitted to the data. These analyses were run using LEM (Vermunt, 1997), a program for log-linear analysis with missing data that allows data from triads that have not been completely genotyped to be included in the analysis. 
The association between LSL and haplotypes formed by the two MTHFR variants were evaluated using an extension of the log-linear model that provides estimates of single- and double-dose haplotype effects (Gjessing and Lie, 2006). The haplotype analyses were conducted using HAPLIN version 2.1.1 running under R Version 2.5.1 for Windows.

In all log-linear analyses, likelihood ratio tests with uncorrected p-values of $<0.05$ were considered to be of interest. However, given that multiple tests were performed (i.e. $\mathrm{N}=18$, tests of inherited and maternal genetic effects for nine variants) the approach of Benjamini and Hochberg (Benjamini and Hochberg, 1995) was used to control the false discovery rate at 0.05 .

The log-linear analyses were conducted using data from all triads, and in a subset of the data that excluded triads in which the mother reported that she was diabetic or used insulin, was epileptic or used seizure medications, or took the drug Paxil during her pregnancy. Triads in which at least one parent was not non-Hispanic Caucasian were also omitted from this subgroup to minimize the potential for biased assessment of the maternal genotype effects that can result when parents are from different racial/ethnic groups (Mitchell and Weinberg, 2005).

\section{Results}

The study sample included 386 triads in which the case had a left sided cardiac defect and was not diagnosed with a recognized genetic syndrome or chromosomal abnormality (Table 1). The most common diagnoses among the cases were hypoplastic left heart syndrome (45.9\%), coarctation of the aorta (32.6\%) and aortic valve stenosis (19.9\%). There was a predominance of males among the cases (62.9\%), as is seen in the general population of cardiac patients (Ferencz and others, 1997) and, in the majority, both parents were reported to be non-Hispanic Caucasian. Maternal diabetes (pre-pregnancy or gestational) or the use of insulin $(\mathrm{N}=6)$, epilepsy or the use of a seizure medication $(\mathrm{N}=2)$, or use of Paxil $(\mathrm{N}=1)$ was reported in $2.3 \%$ of the triads. The majority of cases $(62.5 \%)$ were born in 1999 or later and thus, would have been conceived following mandatory folic acid fortification of the food supply in the United States.

Members of the study triads ( $\mathrm{n}=979$ DNA samples) were genotyped for nine variants (Table 2 ). The genotype call rates ranged from $94 \%-97 \%$. The proportion of samples that provided discrepant results on repeat genotypes ranged from $0 \%$ to $0.8 \%$, and the proportion of triads with genotype combinations that were incompatible with Mendelian inheritance ranged from $0.0 \%$ to $2.3 \%$. All genotype data from families that included at least one genotype combination that was incompatible with Mendelian inheritance were omitted from all analyses ( $\mathrm{N}=63$ samples from 21 triads). In addition, all genotype data from individual samples that failed or provided discrepant results on repeat genotyping for four or more of the genotyped variants were omitted from all analyses ( $\mathrm{N}=21$ samples). The number of useable genotypes for each of the variants ranged from $855-891$. The observed genotype distributions in case individuals and their mothers and fathers are presented in Supplementary Table 1.

Log-linear analyses of individual variants and haplotypes formed by the two MTHFR variants were performed using data from all triads and a subset of triads selected to minimize heterogeneity and bias (see Methods). However, as the results obtained from these two sets of analyses were similar, only the results of the analyses using the full dataset are presented. The distribution of the analyzed triads, by genotypes of the mother, father and case, for each variant are provided in Supplementary Table 2. 
Estimates of relative risk of LSL and 95\% confidence intervals for the inherited and maternal genotypes, the likelihood ratio test statistics and associated p-values for the model comparisons for each variant are summarized in Table 3. A borderline significant association was observed between LSL and case genotype for the BHMT G742A variant (unadjusted $\mathrm{p}=0.06$ ). Among cases, individuals with $B H M T 742 \mathrm{GA}$ and $A A$ genotypes were at decreased risk relative to cases with the $\mathrm{GG}$ genotype $\left(\mathrm{RR}_{\mathrm{GA}}\right.$ vs. $\mathrm{GG}=0.91,95 \% \mathrm{CI} 0.67-$ $1.25 ; \mathrm{RR}_{\mathrm{AA}}$ vs. $\left.\mathrm{GG}=0.50,95 \% \mathrm{CI} 0.27-0.93\right)$. A single association with an unadjusted $\mathrm{p}$ value $<0.05$ was also observed between LSL and maternal genotype. Specifically, the risk of having a child with a LSL was decreased among women with the MTR AG and GG

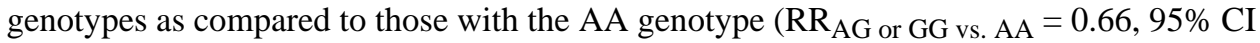
$0.48-0.93, p=0.01$. A dominant model was used for this variant due to the small number of mothers of cases $(n=4)$ with the $\mathrm{GG}$ genotype). However, neither of these associations achieved significance when the false discovery rate was controlled at 0.05 (case BHMT G742A, $\mathrm{p}=0.06>0.003$; maternal MTR A2756G, $\mathrm{p}=0.01>0.003$ ). Analyses of the haplotypes formed by the two MTHFR variants provided no evidence on an affect of either the case or maternal haplotype on the risk of LSL.

\section{Discussion}

The most extensively studied folate variant, MTHFR C677T, has been inconsistently associated with the risk of CHD (van Beynum and others, 2007). The results of our study, as well as those of the single previous study of LSL and MTHFR C677T (McBride and others, 2004), indicate that this variant is not strongly related to the risk of LSL.

The MTHFR A1298C variant has also been inconsistently associated with the risk of CHD. While this variant was not strongly related to the risk of LSL in this study, the two largest studies of this variant and CHD risk identified an association with conotruncal malformations (Goldmuntz and others, 2008) and with a group of CHD including septal, conotruncal and LSL (Hobbs and others, 2006). Hence, the MTHFR A1298C variant may only be associated with specific subsets of CHD and, therefore, difficult to detect in study samples that include heterogeneous CHD phenotypes.

Our analyses of these data also provide little evidence of an association between LSL and either the inherited or maternal genotype for MTRR A66G, MCP1 (-A2518G), TCN2 C777G, SHMT C1420T, or NOS3 G894T. Of these variants, only MTRR A66G, TCN2 C776G and NOS3 G894T have previously been assessed as risk factors for CHD and none of these variants have previously been evaluated in a sample restricted to include only LSL. Consistent with the results of our analyses, previously published studies provide no compelling evidence that either the MTRR A66G (van Beynum and others, 2006; VerkleijHagoort and others, 2008), or the TCN2 C777G (Verkleij-Hagoort and others, 2008) variant has a significant, independent effect on the risk of CHD. The two previous studies of NOS3 variants and CHD risk provided inconsistent results (Shaw and others, 2005; van Beynum and others, 2008).

Our analyses provided some evidence that the MTR A2756G variant may influence the risk of LSL via the maternal genotype and suggested that the $2756 \mathrm{G}$ allele acts in a dominant manner such that women with the AG or GG genotypes have a reduced risk of having a child affected with a left sided cardiac defect as compared to women with the AA genotype. The maternal MTR A2756G genotype has been associated with the risk of several other birth defects including conotruncal heart defects (Goldmuntz and others, 2008), neural tube defects (Doolin and others, 2002) and facial clefts (Mostowska and others, 2006). However, in contrast to our finding for LSLs, the maternal MTR AG and/or GG genotypes appear to be associated with increased risk of these malformations among offspring. While it is possible 
that this variant is associated with increased risk of some birth defects and decreased risk of others, it seems more likely that the observed association with LSL represents a falsepositive finding, as suggested by the failure of this association to achieve statistical significance when the false discovery rate was controlled at 0.05 .

Our analyses also provided some evidence that the BHMT G742A variant may influence the risk of LSL via the inherited genotype, and suggested that the 742AA genotype was associated with decreased risk of LSL compared to the GG genotype. In a large study of conotruncal heart defects, no association with this variant was observed (Goldmuntz and others, 2008) and studies assessing the association of BHMT variants and the risk of neural tube defects have provided conflicting results (Boyles and others, 2006; Morin and others, 2003; Zhu and others, 2005). While it is possible that this variant is associated with the risk of LSL and not conotruncal heart defects, it seems likely that this association also represents a false-positive finding.

This report summarizes the largest and most comprehensive study of the relationship between folate-related genes and LSL to date. Our analyses provide little evidence that the risk of LSL is influenced by the effects of the evaluated folate-related gene variants. However, the possibility that other folate-related gene variants confer risk, or that folaterelated gene variants exert small effects on risk and/or effects that are mediated through other risk factors (e.g. gene-gene, gene-environment interactions) cannot be excluded based on our analyses. Analyses based on larger study samples with carefully defined cardiac phenotypes and additional folate-related gene variants are clearly warranted to define the relationship between folate and CHD risk. Furthermore, studies large enough to permit well powered analyses of gene-gene interaction will be of great value given the inter-relationship between folate pathway gene members. Such studies are critical given the potential to identify an at-risk CHD population that might benefit from simple, targeted intervention.

\section{Supplementary Material}

Refer to Web version on PubMed Central for supplementary material.

\section{Acknowledgments}

Grant support: NIH/NHLBI HL74094 (EG and LEM). This project was also supported by Grant Number M01RR-000240 and UL1-RR-024134 from the National Center for Research Resources. The content is solely the responsibility of the authors and does not necessarily represent the official views of the National Center for Research Resources or the National Institutes of Health.

\section{Literature Cited}

Benjamini Y, Hochberg Y. Controlling the false discovery rate: a practical and powerful approach to multiple testing. Journal of the Royal Statistical Society Series B (Methodological). 1995; 57(1): 289-300.

Boneva RS, Botto LD, Moore CA, Yang Q, Correa A, Erickson JD. Mortality associated with congenital heart defects in the United States: trends and racial disparities, 1979-1997. Circulation. 2001; 103(19):2376-2381. [PubMed: 11352887]

Botto LD, Lin AE, Riehle-Colarusso T, Malik S, Correa A. Seeking causes: Classifying and evaluating congenital heart defects in etiologic studies. Birth Defects Res A Clin Mol Teratol. 2007; 79(10): 714-727. [PubMed: 17729292]

Botto LD, Mulinare J, Erickson JD. Occurrence of congenital heart defects in relation to maternal mulitivitamin use. Am J Epidemiol. 2000; 151(9):878-884. [PubMed: 10791560]

Botto LD, Mulinare J, Erickson JD. Do multivitamin or folic acid supplements reduce the risk for congenital heart defects? Evidence and gaps. Am J Med Genet A. 2003; 121A(2):95-101. [PubMed: 12910485] 
Boyles AL, Billups AV, Deak KL, Siegel DG, Mehltretter L, Slifer SH, Bassuk AG, Kessler JA, Reed MC, Nijhout HF, George TM, Enterline DS, Gilbert JR, Speer MC. Neural tube defects and folate pathway genes: family-based association tests of gene-gene and gene-environment interactions. Environ Health Perspect. 2006; 114(10):1547-1552. [PubMed: 17035141]

Christianson, A.; Howson, CP.; Modell, B. March of Dimes Global Report on Birth Defects. 2006. http://wwwmarchofdimescom/MOD-Report-PFpdf

Corone P, Bonaiti C, Feingold J, Fromont S, Berthet-Bondet D. Familial congenital heart disease: how are the various types related? Am J Cardiol. 1983; 51(6):942-945. [PubMed: 6829469]

Cripe L, Andelfinger G, Martin LJ, Shooner K, Benson DW. Bicuspid aortic valve is heritable. J Am Coll Cardiol. 2004; 44(1):138-143. [PubMed: 15234422]

Doolin MT, Barbaux S, McDonnell M, Hoess K, Whitehead AS, Mitchell LE. Maternal genetic effects, exerted by genes involved in homocysteine remethylation, influence the risk of spina bifida. Am J Hum Genet. 2002; 71(5):1222-1226. [PubMed: 12375236]

Ferencz C, Boughman JA, Neill CA, Brenner JI, Perry LW. Congenital cardiovascular malformations: questions on inheritance. Baltimore-Washington Infant Study Group. J Am Coll Cardiol. 1989; 14(3):756-763. [PubMed: 2768723]

Ferencz, C.; Correa-Villasenor, A.; Loffredo, CA.; Wilson, PD. Genetic and Environmental Risk Factors of Major Cardiovascular Malformations: The Baltimore-Washington Infant Study: 19811989. Armonk: Futura Publishing Company, Inc.; 1997. Left-sided obstructive lesions; p. 166-227.

Fraser FC, Hunter AD. Etiologic relations among categories of congenital heart malformations. Am J Cardiol. 1975; 36(6):793-796. [PubMed: 1199935]

Gjessing HK, Lie RT. Case-parent triads: estimating single- and double-dose effects of fetal and maternal disease gene haplotypes. Ann Hum Genet. 2006; 70(Pt 3):382-396. [PubMed: 16674560]

Goldmuntz E, Woyciechowski S, Renstrom D, Lupo PJ, Mitchell LE. Variants of folate metabolism and the risk of conotruncal cardiac defects. Circulation Cardiovascular Genetics. 2008; 1:126-132. [PubMed: 20031554]

Hinton RB Jr, Martin LJ, Tabangin ME, Mazwi ML, Cripe LH, Benson DW. Hypoplastic left heart syndrome is heritable. J Am Coll Cardiol. 2007; 50(16):1590-1595. [PubMed: 17936159]

Hobbs CA, James SJ, Parsian A, Krakowiak PA, Jernigan S, Greenhaw JJ, Lu Y, Cleves MA. Congenital heart defects and genetic variants in the methylenetetrahydroflate reductase gene. $J$ Med Genet. 2006; 43(2):162-166. [PubMed: 15951337]

Jenkins KJ, Correa A, Feinstein JA, Botto L, Britt AE, Daniels SR, Elixson M, Warnes CA, Webb CL. Noninherited risk factors and congenital cardiovascular defects: current knowledge: a scientific statement from the American Heart Association Council on Cardiovascular Disease in the Young: endorsed by the American Academy of Pediatrics. Circulation. 2007; 115(23):2995-3014. [PubMed: 17519397]

Lewin MB, McBride KL, Pignatelli R, Fernbach S, Combes A, Menesses A, Lam W, Bezold LI, Kaplan N, Towbin JA, Belmont JW. Echocardiographic evaluation of asymptomatic parental and sibling cardiovascular anomalies associated with congenital left ventricular outflow tract lesions. Pediatrics. 2004; 114(3):691-696. [PubMed: 15342840]

McBride KL, Fernbach S, Menesses A, Molinari L, Quay E, Pignatelli R, Towbin JA, Belmont JW. A family-based association study of congenital left-sided heart malformations and 5,10 methylenetetrahydrofolate reductase. Birth Defects Res A Clin Mol Teratol. 2004; 70(10):825830. [PubMed: 15390319]

McBride KL, Pignatelli R, Lewin M, Ho T, Fernbach S, Menesses A, Lam W, Leal SM, Kaplan N, Schliekelman P, Towbin JA, Belmont JW. Inheritance analysis of congenital left ventricular outflow tract obstruction malformations: Segregation, multiplex relative risk, and heritability. Am J Med Genet A. 2005; 134A(2):180-186. [PubMed: 15690347]

Mitchell LE, Weinberg CR. Evaluation of offspring and maternal genetic effects on disease risk using a family-based approach: the "pent" design. Am J Epidemiol. 2005; 162(7):676-685. [PubMed: 16093287]

Morin I, Platt R, Weisberg I, Sabbaghian N, Wu Q, Garrow TA, Rozen R. Common variant in betainehomocysteine methyltransferase (BHMT) and risk for spina bifida. Am J Med Genet A. 2003; 119A(2):172-176. [PubMed: 12749058] 
Mostowska A, Hozyasz KK, Jagodzinski PP. Maternal MTR genotype contributes to the risk of nonsyndromic cleft lip and palate in the Polish population. Clin Genet. 2006; 69(6):512-517. [PubMed: 16712703]

Pei L, Zhu H, Zhu J, Ren A, Finnell RH, Li Z. Genetic variation of infant reduced folate carrier (A80G) and risk of orofacial defects and congenital heart defects in China. Ann Epidemiol. 2006; 16(5):352-356. [PubMed: 16019224]

Pierpont ME, Basson CT, Benson DW Jr, Gelb BD, Giglia TM, Goldmuntz E, McGee G, Sable CA, Srivastava D, Webb CL. Genetic basis for congenital heart defects: current knowledge: a scientific statement from the American Heart Association Congenital Cardiac Defects Committee, Council on Cardiovascular Disease in the Young: endorsed by the American Academy of Pediatrics. Circulation. 2007; 115(23):3015-3038. [PubMed: 17519398]

Shaw GM, Iovannisci DM, Yang W, Finnell RH, Carmichael SL, Cheng S, Lammer EJ. Risks of human conotruncal heart defects associated with 32 single nucleotide polymorphisms of selected cardiovascular disease-related genes. Am J Med Genet A. 2005; 138(1):21-26. [PubMed: 16100725]

Shaw GM, Zhu H, Lammer EJ, Yang W, Finnell RH. Genetic variation of infant reduced folate carrier (A80G) and risk of orofacial and conotruncal heart defects. Am J Epidemiol. 2003; 158(8):747752. [PubMed: 14561664]

van Beynum IM, den Heijer M, Blom HJ, Kapusta L. The MTHFR 677C->T polymorphism and the risk of congenital heart defects: a literature review and meta-analysis. Qjm. 2007; 100(12):743753. [PubMed: 17965089]

van Beynum IM, Kouwenberg M, Kapusta L, den Heijer M, van der Linden IJ, Daniels O, Blom HJ. MTRR 66A $>\mathrm{G}$ polymorphism in relation to congenital heart defects. Clin Chem Lab Med. 2006; 44(11):1317-1323. [PubMed: 17087642]

van Beynum IM, Mooij C, Kapusta L, Heil S, den Heijer M, Blom HJ. Common 894G>T single nucleotide polymorphism in the gene coding for endothelial nitric oxide synthase (eNOS) and risk of congenital heart defects. Clin Chem Lab Med. 2008; 46(10):1369-1375. [PubMed: 18844489]

Verkleij-Hagoort AC, van Driel LM, Lindemans J, Isaacs A, Steegers EA, Helbing WA, Uitterlinden AG, Steegers-Theunissen RP. Genetic and lifestyle factors related to the periconception vitamin B12 status and congenital heart defects: a Dutch case-control study. Mol Genet Metab. 2008; 94(1):112-119. [PubMed: 18226574]

Vermunt, JK. LEM: a general program for the analysis of categorical data. Tilberg University; 1997.

Weinberg CR, Wilcox AJ, Lie RT. A log-linear approach to case-parent-triad data: assessing effects of disease genes that act either directly or through maternal effects and that may be subject to parental imprinting. Am J Hum Genet. 1998; 62(4):969-978. [PubMed: 9529360]

Zhu H, Curry S, Wen S, Wicker NJ, Shaw GM, Lammer EJ, Yang W, Jafarov T, Finnell RH. Are the betaine-homocysteine methyltransferase (BHMT and BHMT2) genes risk factors for spina bifida and orofacial clefts? Am J Med Genet A. 2005; 135(3):274-277. [PubMed: 15887275] 
Table 1

Characteristics of LSL cases and their parents

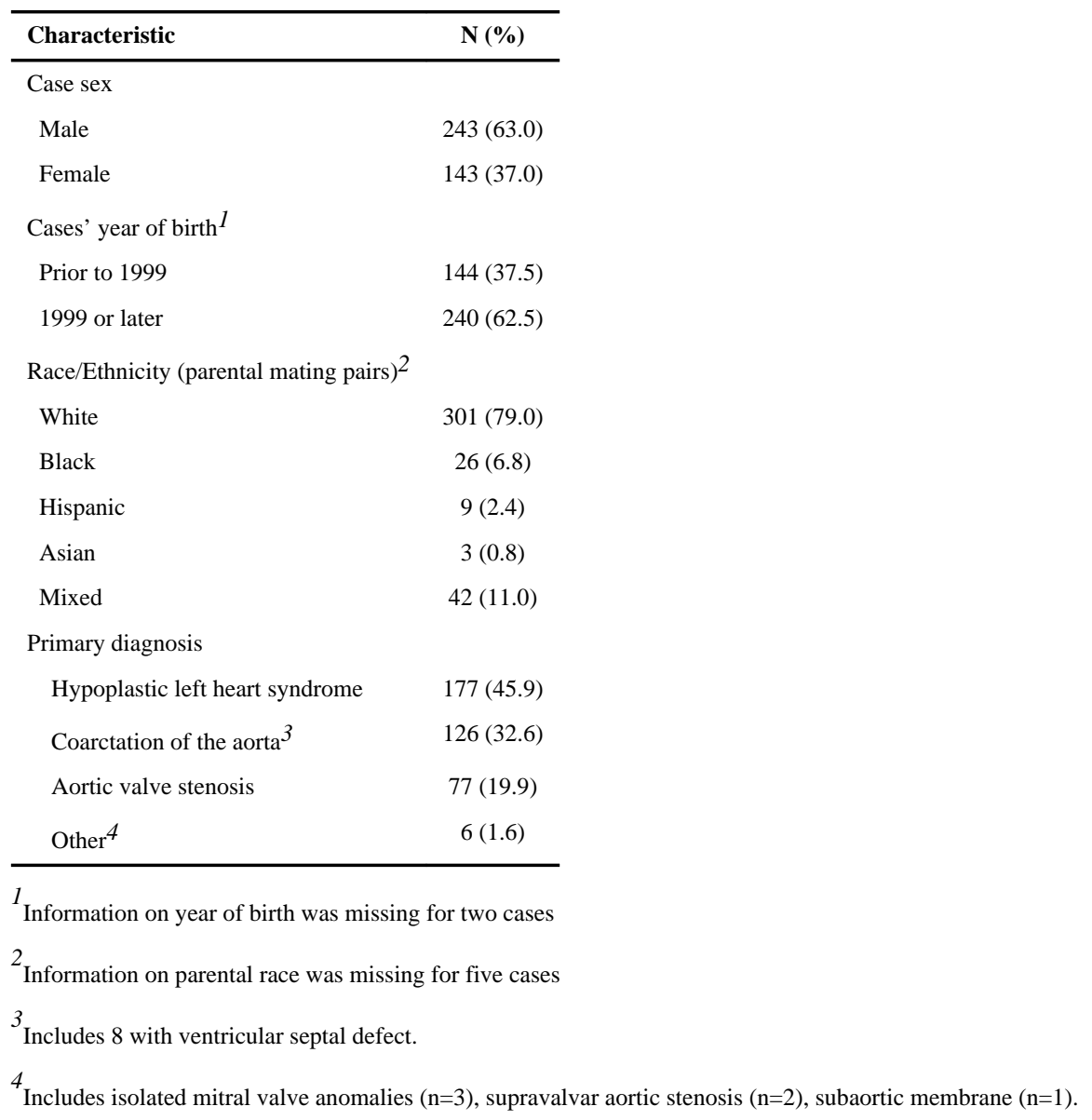




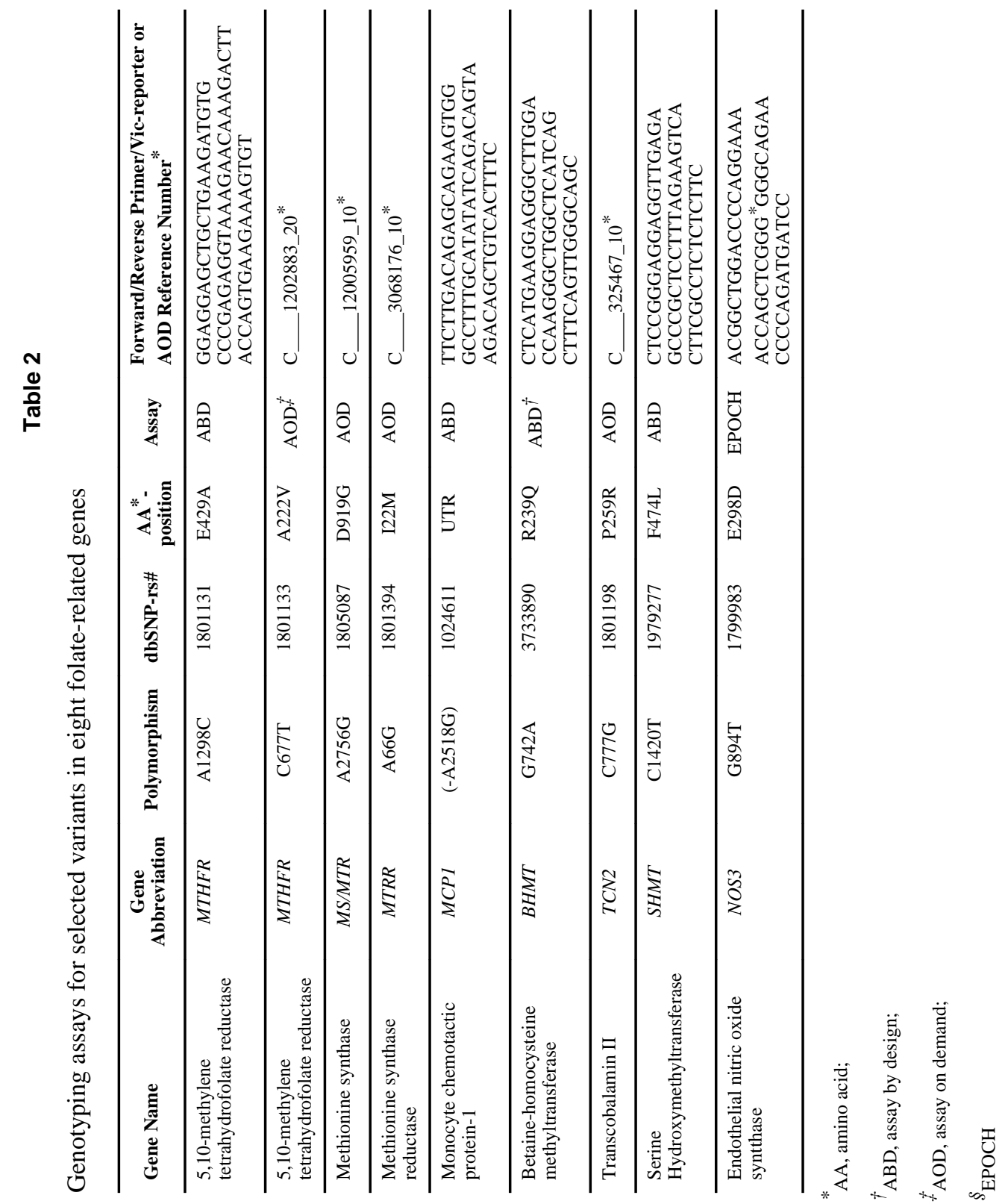

Birth Defects Res A Clin Mol Teratol. Author manuscript; available in PMC 2011 January 1. 


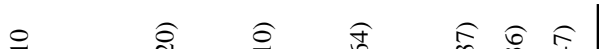

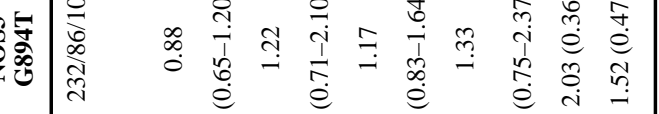

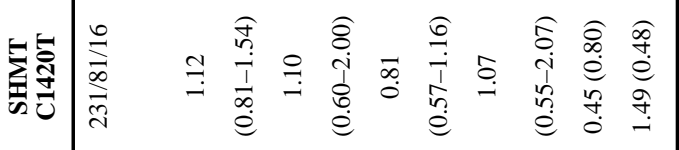

)

은

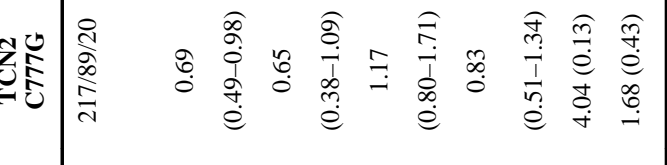

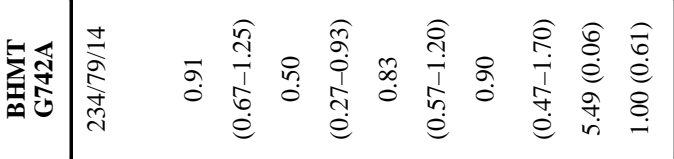

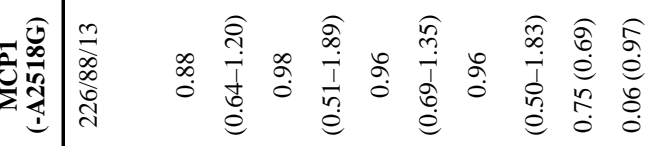

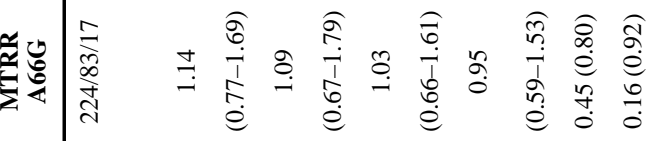

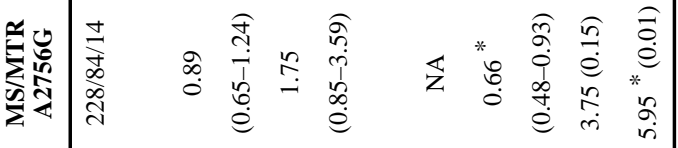

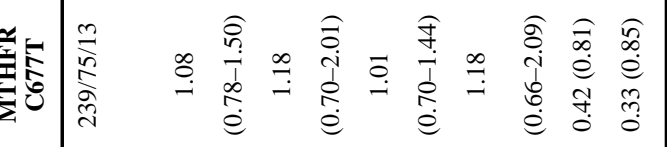

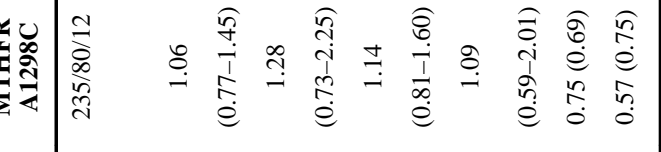

